\title{
Mechanism-Guided Discovery of an Esterase Scaffold with Promiscuous Amidase Activity ${ }^{\dagger}$
}

\author{
Charlotte Kürten ${ }^{1}$, Bengt Carlberg ${ }^{1}$ and Per-Olof Syrén ${ }^{1,2, *}$ \\ 1 Science for Life Laboratory, School of Biotechnology, Division of Proteomics and Nanobiotechnology, \\ KTH Royal Institute of Technology, 17121 Stockholm, Sweden; charlotte.kurten@scilifelab.se (C.K.); \\ bencar@kth.se (B.C.) \\ 2 School of Chemical Science and Engineering, Division of Applied Physical Chemistry, \\ KTH Royal Institute of Technology, 10044 Stockholm, Sweden \\ * Correspondence: per-olof.syren@biotech.kth.se; Tel.: +46-70-340-4990 \\ + Dedicated to Romas Kazlauskas on the occasion of his 60th birthday.
}

Academic Editors: David D. Boehr and Keith Hohn

Received: 29 March 2016; Accepted: 9 June 2016; Published: 18 June 2016

\begin{abstract}
The discovery and generation of biocatalysts with extended catalytic versatilities are of immense relevance in both chemistry and biotechnology. An enhanced atomistic understanding of enzyme promiscuity, a mechanism through which living systems acquire novel catalytic functions and specificities by evolution, would thus be of central interest. Using esterase-catalyzed amide bond hydrolysis as a model system, we pursued a simplistic in silico discovery program aiming for the identification of enzymes with an internal backbone hydrogen bond acceptor that could act as a reaction specificity shifter in hydrolytic enzymes. Focusing on stabilization of the rate limiting transition state of nitrogen inversion, our mechanism-guided approach predicted that the acyl hydrolase patatin of the $\alpha / \beta$ phospholipase fold would display reaction promiscuity. Experimental analysis confirmed previously unknown high amidase over esterase activity displayed by the first described esterase machinery with a protein backbone hydrogen bond acceptor to the reacting $\mathrm{NH}$-group of amides. The present work highlights the importance of a fundamental understanding of enzymatic reactions and its potential for predicting enzyme scaffolds displaying alternative chemistries amenable to further evolution by enzyme engineering.
\end{abstract}

Keywords: enzyme promiscuity; enzyme catalysis; biocatalysis; reaction mechanisms; molecular modeling; amidase; esterase

\section{Introduction}

Biocatalysis shows great potential for shaping a more sustainable society by replacing petroleum-dependent harsh chemical synthesis with mild and green enzymatic processes [1-4] that accelerate catalysis by up to $10^{26}$-fold [5] compared to the corresponding uncatalyzed reaction. The discovery [6-8] and engineering [9-11] of enzymes fueled by the formidable development in high-throughput biotechnology has allowed for tailored manufacturing of materials [12], medicines [13], and fine chemicals [14]. However, developing the full potential of biocatalysis and synthetic biology is dependent on exploring hitherto novel biochemistries $[4,15]$ and reaction mechanisms [16] that expand the catalytic capabilities currently found in nature [15]. Interestingly, many enzymes display alternative chemistries and reaction mechanisms in addition to their natural substrate and reaction specificities [17]. This phenomenon, collectively known as "promiscuity" [18], presumably allows for an increased fitness of the organism through the evolution of novel catalytic functions. Some prominent examples include the $\alpha, \beta$-hydrolase fold [19] that is capable of harnessing 17 different reaction mechanisms [20], P450 monooxygenase-catalyzed cyclization [21], 
cyclopropanation [14], and $\gamma$-humulene synthase that generates 52 different natural products starting from the same polyisoprene substrate [22]. As accelerating promiscuous activities through enzyme engineering constitutes a cornerstone for expanding the catalytic scope of enzymes [15], an enhanced fundamental understanding of the molecular mechanisms underpinning the evolution of the catalytic function is desired. Atomistic details on the process by which protein sequence, structure, and function evolves has allowed researchers to predict enzyme activities in silico [23,24] and could furthermore illuminate how modern enzymes specialized upon diverging from ancient generalists. Herein, we pursued a mechanism-guided in silico search of a minimalistic key catalytic motif comprised of an enzyme-assisted hydrogen bond acceptor in hydrolases. This led to the identification of an esterase scaffold that displays high and previously unreported promiscuous amidase over esterase activity in a non-canonical $\alpha / \beta$ fold. The presented results thus highlight the importance of a fundamental understanding of enzyme catalysis for the discovery and design of new functions [4].

Esterase-catalyzed amide bond hydrolysis constitutes an interesting model system to expand our fundamental understanding of catalytic promiscuity at the Ångström scale. This is because proteases and amidases, which cleave both esters and amides with high efficiency (relative activity $10^{3}$ due to the resonance stabilization of amides [25]), capitalize on the additional hydrogen sitting on the reacting nitrogen atom of amide substrates. Amidases afford hydrogen bond formation to the reacting NH-group in the transition state (TS) [26], which results in efficient amidase activity (Figure 1, left), regardless of protein fold, reaction mechanism, or topology of catalytic dyads/triads [27] displayed by amidases [28].

In contrast, esterases have been found to lack an enzyme-assisted hydrogen bond acceptor for this key interaction, which results in low or even absent promiscuous activities towards amide-based biochemistries [26]. Inspired by the recently acquired detailed mechanistic knowledge of these at first glimpse analogous chemistries, and in an effort to shed additional light on their possible evolution, which still remains elusive $[29,30]$, we undertook a simplistic approach aiming for the discovery of key mechanistic interactions in esterases that could serve as a specificity shifter. In principle, two fundamentally different strategies to obtain enzyme scaffolds with enhanced catalytic specificities and versatilities could be envisioned (Figure 1). The first one, the ancestral gene resurrection (Figure 1, right), is based on protein families that comprise sufficient sequence diversity and constitutes an innovative pathway to shed light on the evolution of catalytic specificity [31]. Moreover, bioinformatic analysis could provide an important insight on how sequence and function space are intertwined. This technique has recently been used by researchers to reconstruct ancient $\alpha, \beta$-hydrolases that were found to be more promiscuous than present enzymes [30]. In another study, the reconstruction of extinct $\beta$-lactamases afforded highly thermostable scaffolds [32]. As we were previously unable to identify enzyme-assisted hydrogen bond acceptors in esterases belonging to the $\alpha, \beta$-hydrolases [26], we reasoned that analyzing alternative and existing enzyme folds would be a relevant second strategy for the identification of promiscuous esterase scaffolds that could serve as a starting point for further engineering (represented by the forward gear, Figure 1, left). Capitalizing on a previously calculated transition state structure of nitrogen inversion [29], in silico analysis readily identified an enzyme-assisted hydrogen bond acceptor in patatin, an esterase from potato with a unique Ser/Asp catalytic dyad that does not display an $\alpha, \beta$-hydrolase fold [33]. Biochemical characterization unraveled high and previously unknown amidase over esterase activity in accordance with our predictions. The present work thus provides unique snapshots into the possible evolution of efficient amidase activities at the microscopic level. 


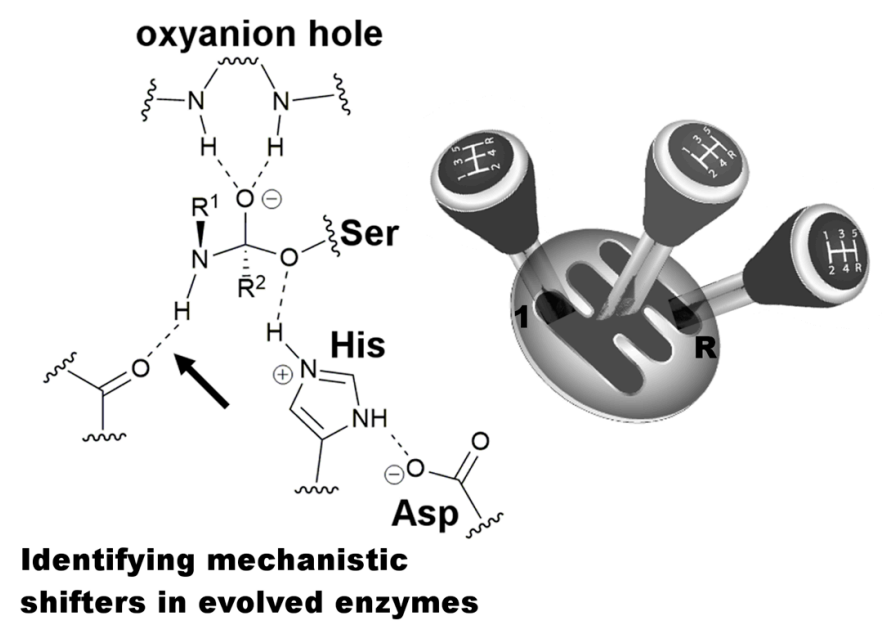

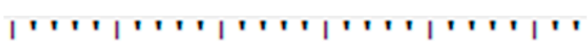

$70 \quad 80$

SCDFLLSLCYPEGYWWAELEANVTLTA SCDFLFSCQYAEGYWWAELESNVTMTA AVEYILSC $\subset$ RDEGYWWGPILSNVTMEA ACDWLIGC CKPDGHWVGAVESNASMEA ARDRLISICHLEGYWVEELEADCTIPA ARDRLISLCHLEGYWVEELEADCTIPA ATC GVLGE ÇSSGHWVEELEADCTIPA ARAALLGYRRDDGHWVFELEADCTIPA ATRALLER C C DGHWVELLEADATIPA AHTAFEGALNGMTFYVGIQAEDGHWTG

Ancestral enzyme reconstruction

Figure 1. Two different strategies to discover novel enzyme scaffolds with enhanced promiscuous activity. Left: Boosting promiscuous activity by focusing on the in silico discovery $[23,24]$ and engineering [34] of key mechanistic structural elements in modern enzymes is represented by the forward gear. This is exemplified by focusing on a hydrogen bond acceptor (arrow) that could act as a shifter for enhanced amidase over esterase activity by facilitating nitrogen inversion (structure shown), a key step in amide bond hydrolysis [26]. We have shown that the previously unacknowledged key hydrogen bond donated by the reacting $\mathrm{NH}$-group facilitates nitrogen inversion, the overall rate limiting step of enzyme catalyzed amide bond hydrolysis [26,27,35]. As the specific orientation of the single lone pair of the reacting nitrogen is governed by stereoelectronic effects [36], nitrogen inversion is required during biocatalysis for the generation of a productive second tetrahedral intermediate. In contrast, for ester hydrolysis the additional lone pair sitting on the ester oxygen can readily accept a proton from the catalytic base with only subtle rearrangements. The catalytic triad and oxyanion hole are labeled for a serine hydrolase catalytic machinery. Right: A fundamentally different approach attempts to boost promiscuous activity by reversing evolution through bioinformatic-guided resurrection of ancient and presumably less specific enzymes based on protein sequences that are present today.

\section{Results}

We hypothesized that analyzing esterase scaffolds with different topologies and mechanisms beyond the canonical $\alpha, \beta$-hydrolase fold would be beneficial in our quest to unravel high promiscuous activities based on in silico prediction and mechanistic understanding. This reasoning was supported by the fact that previously analyzed members of the $\alpha, \beta$-hydrolase fold do not provide an enzyme-assisted hydrogen bond acceptor to the reacting $\mathrm{NH}$-group of amides, including the amidase prolyl oligopeptidase that accomplishes accelerated rates by substrate assisted catalysis [26]. We thus turned our attention towards human phospholipase $\mathrm{A}_{2}$, a key player for the cyclooxygenase-dependent biosynthesis of prostaglandins that is well known to possess a structurally distinct $\alpha / \beta$-fold that harbors an exotic [37] Ser/Asp dyad [38]. Interestingly, by docking a transition state structure for nitrogen inversion that we previously [29] obtained in a serine hydrolase using density functional theory (DFT) at the B3LYP/6-31(d,p) level of theory, a potential enzyme-assisted hydrogen bond acceptor could be identified from the crystal structure (Figure $2 \mathrm{a}$ ). The formation of a direct hydrogen bond is of particular interest, as we have previously shown that using water as biobricks to afford bridged and indirect hydrogen bonding to the enzyme can significantly enhance absolute promiscuous activities [29]. The backbone carbonyl of G394 in the phospholipase was several $\AA$ closer to the reacting $\mathrm{NH}$-group of the docked transition state compared to the deshielded acceptor in the I189A variant of C. antarctica lipase B that utilizes two water molecules to achieve unprecedented rate enhancements (Figure 2a) [29]. Thus, the experimental consequences of the potent and proximal acceptor on catalysis would be of interest. However, as the expression of human membrane-associated enzymes could 
constitute a hurdle for experimental biochemical analysis, we expanded our focus to include additional soluble scaffolds displaying the $\alpha / \beta$-phospholipase fold. One such interesting template that could readily be obtained from the protein data bank (PDB) is the closely-related acyl hydrolase patatin (Pat17) [33] from S. cardiophyllum. Patatin displays a Ser/Asp catalytic dyad that gives rise to a flat activity vs. $\mathrm{pH}$ profile, presumably important to allow for catalytic versatility under different physiological conditions in the plant cell and in the defense against parasites mediated through ester hydrolysis [33]. In order to investigate the impact of solvent and enzyme dynamics on potential hydrogen bond formation, 90 ns molecular dynamics (MD) simulations of the second tetrahedral intermediate representing the transition state for nitrogen inversion [26] in patatin were performed in duplicate (Figure 2b, Table 1). A neutral reacting substrate NH-group obstructed the generation of productive catalytic conformations (Figure S1, Supplementary Information) and further accommodated a spatial arrangement corresponding to the first tetrahedral intermediate, which is not representative of rate-limiting nitrogen inversion [26]. Hence, the simulations were conducted using a protonated reacting $\mathrm{NH}$-group as previously described [35].
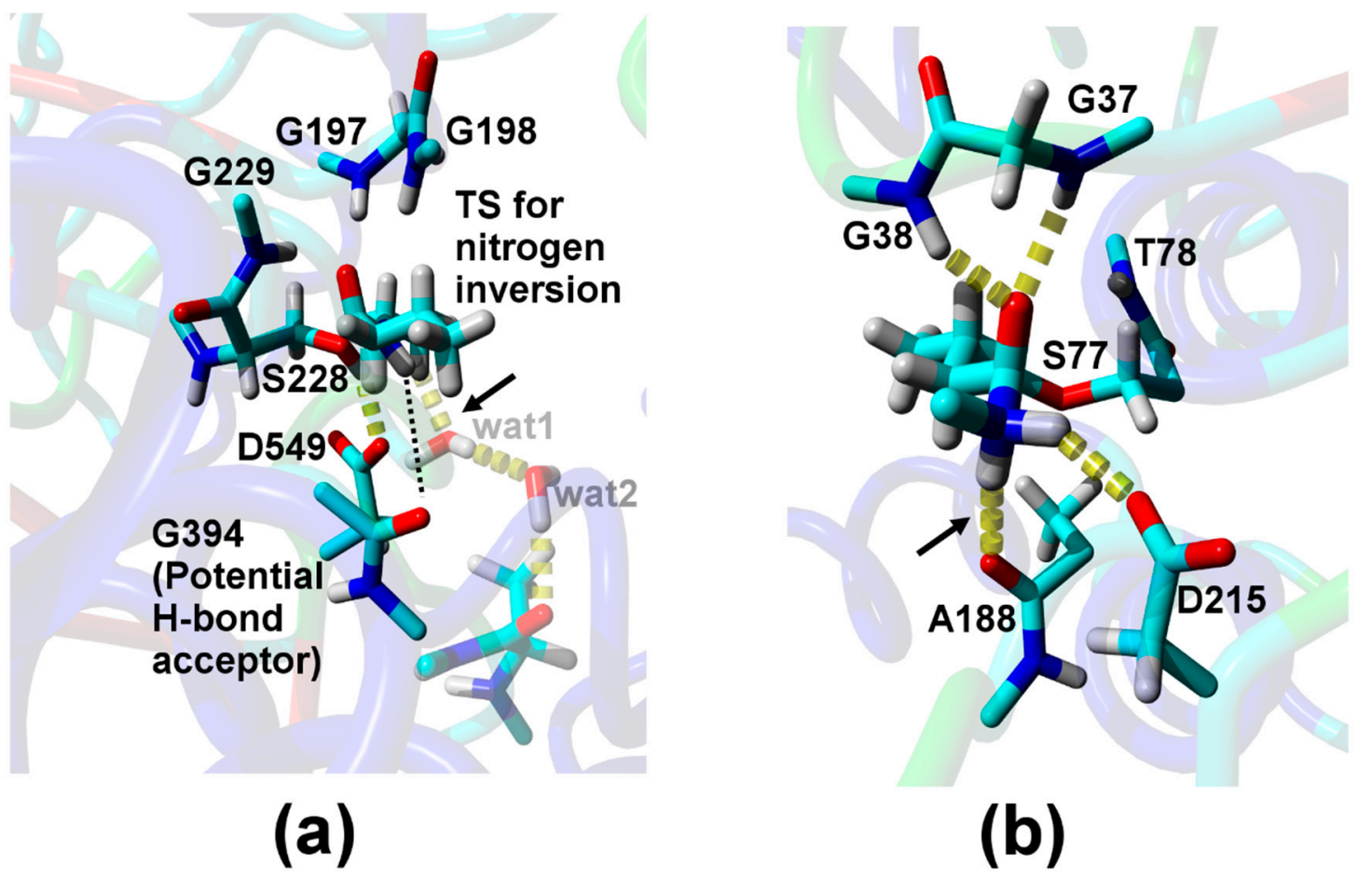

Figure 2. Mechanism-guided discovery of promiscuous enzyme scaffolds. (a) The transition state for nitrogen inversion (bold sticks) calculated using density functional theory (DFT) in the C. antarctica lipase B I189A variant [29] was docked into the crystal structure of human phospholipase $\mathrm{A}_{2}$ (PDB 1CJY [38]). The discovered backbone carbonyl of G394 in human phospholipase $A_{2}$ that could act as a potential hydrogen bond acceptor to the transition state is highlighted by the dotted line (corresponding to a distance of $4.1 \AA$ ). For reference, parts of the C. antarctica lipase B engineered variant is shown in faded sticks highlighting the mechanistically important hydrogen bond for inversion (arrow) mediated through two water molecules [29] and accepted by the more distal and exposed backbone (shaded). The catalytic serine, acid and residues of the oxyanion hole in human phospholipase $\mathrm{A}_{2}$ are labeled. (b) Snapshot from a molecular dynamics (MD) simulation of the second tetrahedral intermediate during acylation of S. cardiophyllum patatin. The key hydrogen bond accepted by the discovered backbone carbonyl of A188 (corresponding to G394 in human phospholipase $A_{2}$ ) facilitating inversion is shown by the arrow. The catalytic serine (S77), aspartic acid (D215), and residues of the oxyanion hole in patatin are labeled. 
Table 1. Probabilities to form the key mechanistic hydrogen bond to the reacting NH-group of the amide substrate in the modeled transition state (TS). ${ }^{\text {a }}$

\begin{tabular}{|c|c|c|}
\hline Relative Probability [\%] ${ }^{b}$ & NH-O ${ }_{\text {acceptor }}$ Distance $[\AA ̊]^{c}$ & $\mathrm{NH}-\mathrm{O}_{\text {acceptor Angle }}\left[{ }^{\circ}\right]^{\mathrm{d}}$ \\
\hline \multicolumn{3}{|c|}{ Direct H-bond to A188 ${ }^{e}$} \\
\hline 2.0 & & $161(136)$ \\
\hline \multicolumn{3}{|c|}{ H-bond via one water ${ }^{f}$} \\
\hline 0.1 & $2.1(2.9)$ & $136(100)$ \\
\hline
\end{tabular}

\begin{abstract}
a Values shown are averages based on $90 \mathrm{~ns}$ MD simulations of the second tetrahedral intermediate that were run in duplicate. ${ }^{\mathrm{b}}$ Relative probability for the formation of a productive transition state for nitrogen inversion stabilized by a hydrogen bond and displaying an $\mathrm{O}-\mathrm{C}-\mathrm{N}-\mathrm{H}$ dihedral angle $>130^{\circ}$. ${ }^{\mathrm{c}}$ Average hydrogen bond length for productive transition states. Average distances for all snapshots are given within brackets for comparison. ${ }^{\mathrm{d}}$ Average angle between the reacting NH-group and the acceptor for productive transition states. Average angles for all snapshots are given within brackets for reference. ${ }^{\mathrm{e}}$ For structures where the hydrogen bond acceptor $\left(\mathrm{O}_{\text {acceptor }}\right)$ is the backbone carbonyl of A188. ${ }^{\mathrm{f}}$ Snapshots for which the acceptor is a water molecule. Structures with more than one bridging water molecule between the TS and the protein were not found.
\end{abstract}

Productive transition states were defined as structures stabilized by a hydrogen bond in a spatial arrangement corresponding to facilitation of the TS for nitrogen inversion [26] thus displaying an $\mathrm{O}-\mathrm{C}-\mathrm{N}-\mathrm{H}$ (i.e. former carbonyl oxygen-carbon- $\mathrm{N}-\mathrm{H}$ ) dihedral angle greater than $130^{\circ}$, which is typically found for amidases [26]. The MD simulations showed that the flexibility of the patatin scaffold allowed for direct hydrogen bond formation between the reacting NH-group of the substrate and the backbone of A188 in the modeled TS (Figure 2b). In contrast a water-mediated hydrogen bond bridging the reacting $\mathrm{NH}$-group and the discovered acceptor was unlikely $(0.1 \%$ relative probability for a water-mediated interaction vs. 2.0\% for a direct enzyme-assisted hydrogen bond, Table 1).

Encouraged by the results from our simplistic in silico approach, we undertook an experimental investigation of the catalytic promiscuity of the patatin scaffold by comparing inherent esterase and amidase activities (Table 2, top). Expression of a codon-optimized gene with an $\mathrm{N}$-terminal His-tag but lacking the $N$-terminal sequence tag [33] in E. coli BL21(DE3) afforded an enriched protein after affinity chromatography (theoretical size $41 \mathrm{kDa}$, Figure S2a, Supplementary Information). Gel filtration resulted in a pure monomer (Figure S2b, Supplementary Information) that was confirmed to be catalytically active by colorimetric detection using $p$-nitrophenyl butyrate as a model substrate. As the enzyme preparation obtained after Ni-NTA affinity chromatography was found to display the same specific activity as the pure monomer (results not shown), all subsequent experimental characterization was performed using Ni-NTA purified protein. Kinetic parameters of ester and amide bond hydrolysis were determined by spectrophotometric analysis using $p$-nitrophenyl butyrate (ester) and $p$-nitrobutyranilide (amide) as substrates (Figure S3, Supplementary Information). The apparent $k_{\text {cat }} / K_{\mathrm{M}}$ representing esterase activity was determined to $21,000 \mathrm{M}^{-1} \cdot \mathrm{s}^{-1}$, illuminating the fact that patatin has a binding pocket for larger acyl groups [33]. A comparison of the initial rates showed that the ratio of amidase over esterase activity of around $2 \times 10^{-5}$ displayed by patatin represents a shift in reaction specificity of 100-fold compared with that of $H$. insolens cutinase and tenfold compared with that of $C$. antarctica Lipase B (Table 2) that are known for their relatively high promiscuous amidase activities. A $40 \mathrm{~ns}$ MD simulation of the tetrahedral intermediate representing acylation of patatin using the ester substrate $p$-nitrophenyl butyrate revealed a similar arrangement of catalytic residues compared to that of the amide substrate. Specifically, the average heavy atom distance of $2.83 \AA$ between the carboxylate oxygen of the catalytic acid and the ester oxygen ( $\mathrm{D} 215 \mathrm{O}-\mathrm{O})$ should be compared to the corresponding value of $2.80 \AA$ for the amide substrate $(\mathrm{D} 215 \mathrm{O}-\mathrm{N})$. The average distances between the catalytic acid and the $\mathrm{O} \gamma$ of the catalytic nucleophile (S77) were also found to be similar (average heavy atom distances of $3.70 \AA$ for the amide substrate and $3.34 \AA$ for the ester respectively). Hence, the displayed amidase over esterase activity by patatin would be in accordance with hydrogen bond formation for the amide substrate, which is not possible for the ester that displays the necessary prerequisites for efficient catalysis, including hydrogen bond formation in the oxyanion 
hole (data not shown). As expected, a catalytic knockout represented by the D215A mutation had no catalytic activity (Figure S4, Supplementary Information). Strikingly, an active site titration of patatin using a phosphonate ester suicide inhibitor showed that only around 3\% of the total enzyme amount was active after expression in E. coli (Figure S5, Supplementary Information). This is perhaps not surprising as previous kinetic analysis of patatin has been based on protein expression in eukaryotic systems [33]. The low concentration of active enzyme prohibited the full determination of apparent $k_{\text {cat }} / K_{\mathrm{M}}$ values for amide bond hydrolysis; consequently, an amide substrate concentration of $1.0 \mathrm{mM}$ was used.

Table 2. Relative experimental promiscuous activities for patatin in comparison with other promiscuous esterases based on using $p$-nitrophenyl butyrate (ester) and $p$-nitrobutyranilide (amide) as substrates.

\begin{tabular}{|c|c|c|c|c|}
\hline Biocatalyst & $\begin{array}{c}k_{\text {cat }} / K_{\mathrm{M}}, \text { Amide } \\
\left(\mathrm{s}^{-1} \cdot \mathbf{M}^{-1}\right)\end{array}$ & $\begin{array}{c}k_{\text {cat }} / K_{\mathrm{M}}, \text { Ester } \\
\left(\mathrm{s}^{-1} \cdot \mathbf{M}^{-1}\right)\end{array}$ & $\begin{array}{c}\text { Relative Amidase } \\
\text { over Esterase Activity }\end{array}$ & References \\
\hline S. cardiophyllum patatin & $\begin{array}{c}\approx 0.45 \\
\left(V_{0}=0.00045 \mathrm{~s}^{-1}\right)^{[\mathrm{a}]}\end{array}$ & 20,900 & $\begin{array}{c}2.0 \times 10^{-5} \\
\left(3.0 \times 10^{-5}\right)^{[b]}\end{array}$ & This work \\
\hline B. subtilis esterase & 0.46 & 4200 & $1.1 \times 10^{-4}$ & [39] \\
\hline H. insolens cutinase & 0.09 & 770,000 & $1.2 \times 10^{-7}$ & [34] \\
\hline C. antarctica lipase B wild type & 0.08 & 32,000 & $2.5 \times 10^{-6}$ & [34] \\
\hline C. antarctica lipase B I189A & 1.8 & 12,343 & $1.5 \times 10^{-4}$ & [29] \\
\hline Proteases & - & - & - & - \\
\hline Chymotrypsin & - & - & $1.0 \times 10^{-4[\mathrm{c}]}$ & [25] \\
\hline
\end{tabular}

${ }^{\text {[a] }}$ Due to low activity the estimated $k_{\text {cat }} / K_{\mathrm{M}}$ value is based on a single substrate concentration of $1 \mathrm{mM}$ and the corresponding initial rate is given within brackets. The initial rate is based on a biological duplicate. ${ }^{[b]}$ For reference, the relative promiscuous activity based on initial rates using the ester and amide substrate at a concentration of $1 \mathrm{mM}$ is given within brackets. ${ }^{[c]}$ Corresponding to the difference in reactivity for the cleavage of a $p$-nitroaniline and $p$-nitrophenol moiety respectively, which was found to be essentially the same as that of un-activated substrates [25]. For $k_{\text {cat }}$, the corresponding ratio is roughly $10^{-3}$.

\section{Discussion}

Evolution is a never-ending experiment for which the impact of new combinations of nucleotides on organism fitness is constantly [40] evaluated. Mutations in genes coding for enzymes thus constitute a cornerstone for acquiring new catalytic functions that for instance provide new mechanisms for defense, detoxification, and signaling [41-43]. Hence, enzyme promiscuity is of immense relevance for the chemical and biotechnological industrial fields for which the development of hitherto unknown biochemical reactions is of central interest [8]. For instance, based on chemical expertise, researchers have successfully discovered novel chemistries for stereoselective carbon-carbon bond formation [14] in existing enzyme scaffolds that can be significantly improved using enzyme engineering [44]. An enhanced understanding of promiscuous activities and their evolution at the molecular level would thus facilitate the transition towards a more sustainable society for which chemical transformations could be replaced by green enzymatic reactions [4]. Biocatalytic chemistries centered on the amide bond are of fundamental industrial importance [45] and have widespread applications ranging from fine chemical synthesis to the generation of biopharmaceuticals [46]. By focusing on the $\alpha / \beta$-phospholipase fold that forms an integral part of binding proteins [47] and that is furthermore capable of harnessing a plethora of activities including acyl transfer in polyketide biosynthetic machineries [48], a previously unknown enzyme-assisted hydrogen bond acceptor for stabilizing nitrogen inversion was discovered (Figure 2). Whereas the molecular mechanisms behind previously reported promiscuous amidase activities in esterase scaffolds (see Table 1 for some examples) are not completely understood or are suggested to depend upon water-mediated interactions [39,49] whose evolutionary role remains unclear [29], the present study reports on the first example of a direct enzyme-assisted hydrogen bond acceptor. In accordance with this minimalistic motif acting as a specificity shifter, experimental analysis of the identified esterase template, which does not encounter amide substrates in nature [33], revealed previously unknown high amidase over esterase activities (Table 2). The absolute amidase rate displayed by wild-type patatin was found to be higher or in the same order of magnitude compared to 
that of other esterases with reported promiscuous amidase activity (Table 2). Moreover, the reaction specificity of around $2 \times 10^{-5}$ for patatin (Table 2) is two orders of magnitude from the theoretical limit of roughly $10^{-3}$ corresponding to the difference in chemical resonance stabilization between an ester and an amide [50]. Although the employed docking approach herein was simplistic, it could in principle be fully automated for in silico screening of many additional scaffolds, a strategy that has successfully been incorporated by other research groups [23,24]. Besides illuminating the potential of using in silico biochemistry for the discovery of novel reactions by a fundamental understanding of enzymes and their reaction mechanisms, the present study could provide a mechanistic piece of the puzzle as to how biocatalysts could acquire higher specificity towards the amide bond, which is more challenging to hydrolyze than esters due to fundamental chemical principles. Using enzyme catalyzed amide bond hydrolysis as a mechanistic example stresses the potential of understanding enzyme promiscuity at the atomistic level for the discovery of previously unreported activities.

\section{Materials and Methods}

\subsection{Sequence/Plasmid}

A codon optimized sequence of wild-type phospholipase patatin17 from S. cardiophyllum (pat17, EC 3.1.1.4, truncated sequence based on PDB 1OXW [33] and without the previously described recognition sequence [33]) was synthesized by GeneArt (see Appendix 4.9 for sequences). The sequence was introduced into a pET28a-(+) vector with an $\mathrm{N}$-terminal $\mathrm{His}_{6}$-tag. The plasmid carries a kanamycin resistance gene and the IPTG-inducible lac-operon for protein expression.

\subsection{Strains and Growth Media}

Escherichia coli top10 (E. coli, genotype: F-mcrA $\Delta$ (mrr-hsdRMS-mcrBC) $\Phi 80$ lacZ $\Delta$ M15 $\Delta$ lacX74 recA1 araD139 $\Delta$ (araleu)7697 galU galK rpsL (StrR) endA1 nupG) was used for plasmid propagation. E. coli BL21 (DE3, genotype: F-ompT hsdSB (rB-, mB-) gal dcm (DE3)) was used for protein expression. Plasmids were transformed by standard heat shock transformation.

Complex 2xYT (16 g/L tryptone, $10 \mathrm{~g} / \mathrm{L}$ yeast extract, $5 \mathrm{~g} / \mathrm{L} \mathrm{NaCl}$ ) supplemented with $50 \mu \mathrm{g} / \mathrm{mL}$ kanamycin was used as cultivation medium. LB-plates $(10 \mathrm{~g} / \mathrm{L}$ tryptone, $5 \mathrm{~g} / \mathrm{L}$ yeast extract, $10 \mathrm{~g} / \mathrm{L}$ $\mathrm{NaCl}, 16 \mathrm{~g} / \mathrm{L}$ Agar) served as solid medium.

\subsection{Mutagenesis}

Qiagen Miniprep kit (Qiagen, Venlo, The Netherlands) was used for plasmid purification. Site directed-mutagenesis for the D215A-knockout (corresponding to D203A in our synthetic and truncated construct) was performed with Agilent Fusion polymerase PfuUltra II (Agilent, Santa Clara, CA, USA) according to standard protocol with the following primers: forward 5'-TTgcgGGTGCCGTTGCGACCG-3', reverse: 5'-CGGCACCcgcAACCAGATTAAATTC-3'.

\subsection{Protein Expression}

2-L baffled flasks containing $600 \mathrm{~mL}$ 2xYT-media, supplemented with $50 \mu \mathrm{g} / \mathrm{mL}$ kanamycin, were inoculated to an $\mathrm{OD}_{600}$ of 0.07 with a liquid pre-culture. The cells were incubated at $37^{\circ} \mathrm{C}$ and $160 \mathrm{rpm}$ until an $\mathrm{OD}_{600}$ of 0.6 reached 0.8. Protein expression was induced by adding $0.1 \mathrm{mM} \mathrm{IPTG}$, and patatin was expressed overnight $(18-20 \mathrm{~h})$ at $18^{\circ} \mathrm{C}$ and $160 \mathrm{rpm}$. Cells were harvested (4500 rpm, $10 \mathrm{~min}$ and $4^{\circ} \mathrm{C}$ ) and pellets were stored at $-80^{\circ} \mathrm{C}$.

\subsection{Protein Extraction and Purification}

Cell pellets were resuspended in $3 \mathrm{~mL} / \mathrm{g}$ Lysis buffer (100 mM KH $\mathrm{PO}_{4} / \mathrm{K}_{2} \mathrm{HPO}_{4} \mathrm{pH}$ 7.5) supplemented with Roche cOmplete, Mini Protease Inhibitor Tablets (Roche, Basel, Switzerland). Cells were lysed by sonification (QSonica sonificator, (Qsonica, Newtown, CT, USA) 3×, time: $50 \mathrm{~s}$, amplitude: $80 \%$, pulse: $1 \mathrm{~s}$ on, $1 \mathrm{~s}$ off) and centrifuged at $18,000 \mathrm{rpm}, 4{ }^{\circ} \mathrm{C}$ for $50 \mathrm{~min}$. An amount 
of $1.5 \mathrm{~mL}$ Ni-NTA agarose beads (Qiagen, Venlo, The Netherlands) were added to the supernatant and incubated on ice for $1 \mathrm{~h}$ (end-over-end mixing). The protein was purified with Ni-NTA affinity chromatography. The protein-bead mixture was transferred to a gravity column and washed with $2 \times 5 \mathrm{~mL}$ wash buffer (50 mM KH $\mathrm{PO}_{4} / \mathrm{K}_{2} \mathrm{HPO}_{4} \mathrm{pH} 7.5,50 \mathrm{mM}$ imidazole). The His 6 -tagged patatin was released with a $6 \times 1 \mathrm{~mL}$ elution buffer $\left(50 \mathrm{mM} \mathrm{KH}_{2} \mathrm{PO}_{4} / \mathrm{K}_{2} \mathrm{HPO}_{4} \mathrm{pH} 7.5,250 \mathrm{mM}\right.$ imidazole). The elution fractions were analyzed using sodium dodecyl sulfate-polyacrylamide gel electrophoresis (Figure S1, Supplementary Information, 10\% Mini PROTEAN TGX-gels, BioRad, Hercules, CA, USA). Elution fractions that showed a signal for patatin were pooled, washed, and concentrated (Centricon, Amicon Ultra-15 Centrifugal Filter Units, Merck Millipore, Billerica, MA, USA) to a final volume of $1.5 \mathrm{~mL}$. Protein concentration was determined by Bradford [51] using the Expedeon BradfordUltra kit (Expedeon, Cambridgeshire, UK), which resulted in typical protein concentrations of $0.3 \mathrm{mg} / \mathrm{mL}$.

\subsection{Size Exclusion Chromatography}

The two prominent protein signals obtained from $\mathrm{His}_{6}$-tag purification (Figure S1a, were separated by size exclusion chromatography using a HiPrep Sephacryl S-400 HR column (GE Healthcare, Uppsala, Sweden) on an ÄKTA purification system (Figure S2). As a running buffer, $50 \mathrm{mM} \mathrm{KH_{2 }} \mathrm{PO}_{4} / \mathrm{K}_{2} \mathrm{HPO}_{4}$, pH 7.5 was used, with a flow rate of $0.5 \mathrm{~mL} / \mathrm{min}$. Enzymatic esterase activity determined after affinity chromatography and after size exclusion chromatography gave the same specific activity.

\subsection{Active Site Titration}

To determine the amount of active sites, fluorescence measurements with the enzyme inhibitor 4-methylumbelliferyl hexylphosphonate were performed as previously described [52]. Fluorescence was determined in opaque 96-well plates with a total volume of $100 \mu \mathrm{L}$ (10 $\mu \mathrm{L}$ inhibitor in acetonitrile $+90 \mu \mathrm{L}$ buffer $\left(50 \mathrm{mM} \mathrm{KH}_{2} \mathrm{PO}_{4} / \mathrm{K}_{2} \mathrm{HPO}_{4} \mathrm{pH} 7.5\right)$ ) per well. Duplicates of 5 and $7.5 \mu \mathrm{M}$ of added enzyme were measured over $\sim 100 \mathrm{~h}$. The amount of active sites was calculated using a 4-methylumbelliferone standard curve (Figure S5, Supplementary Information). Fluorescence measurements were performed with SpectraMax i3x (Molecular Devices, Sunnyvale, CA, USA) with the following settings: 360-nm excitation, 455-nm emission, 6 flashes per read, and 5-mm read height from the top. The average number of active sites corresponded to $3.1 \%$ of the amount of purified protein.

\subsection{Enzyme Activity and Kinetic Data}

Activity measurements of wild-type patatin were performed using ester ( $p$-nitrophenyl butyrate, Sigma-Aldrich, St. Louis, MO, USA) and amide ( $p$-nitrobutyranilide) substrates. Amide synthesis was achieved as previously described [34] by acid chloride chemistry using $p$-nitroaniline and butyryl chloride. Enzymatic hydrolysis was followed spectrophotometrically at $410 \mathrm{~nm}$ in phosphate buffer $\left(50 \mathrm{mM} \mathrm{KH}_{2} \mathrm{PO}_{4} / \mathrm{K}_{2} \mathrm{HPO}_{4}, \mathrm{pH} 7.5\right)$ at $37^{\circ} \mathrm{C}$. An extinction coefficient $\left(\varepsilon_{410 \mathrm{~nm}}\right)$ of $12.5 \times 10^{3} \mathrm{M}^{-1} \cdot \mathrm{cm}^{-1}$ was used for released $p$-nitrophenol taking the ionization equilibria at $\mathrm{pH} 7.5$ into account and assuming $\varepsilon_{410 \mathrm{~nm}}=18000 \mathrm{M}^{-1} \cdot \mathrm{cm}^{-1}$ for the deprotonated form and $\varepsilon_{410 \mathrm{~nm}}=200 \mathrm{M}^{-1} \cdot \mathrm{cm}^{-1}$ for the acid form, respectively [53]. For $p$-nitroaniline, an extinction coefficient of $9.1 \times 10^{3} \mathrm{M}^{-1} \cdot \mathrm{cm}^{-1}$ was used. For measuring ester activity, $50 \mu \mathrm{L}$ His-tag purified enzyme was mixed with $940 \mu \mathrm{L}$ of reaction buffer ( $50 \mathrm{mM} \mathrm{KH}_{2} \mathrm{PO}_{4} / \mathrm{K}_{2} \mathrm{HPO}_{4}, \mathrm{pH}$ 7.5). The reaction was started by adding $10 \mu \mathrm{L}$ of a substrate stock ( $p$-nitrophenyl butyrate in acetonitrile) to a final substrate concentration of $0.25-1.0 \mathrm{mM}$. The ester reaction was monitored for $10 \mathrm{~min}$. To determine promiscuous amidase activity, $300 \mu \mathrm{L}$ His-purified enzyme was mixed with $690 \mu \mathrm{L}$ of reaction buffer $\left(50 \mathrm{mM} \mathrm{KH}_{2} \mathrm{PO}_{4} / \mathrm{K}_{2} \mathrm{HPO}_{4}, \mathrm{pH} 7.5\right)$. The reaction was initiated by adding $10 \mu \mathrm{L}$ of amide substrate stock solution ( $p$-nitrobutyranilide in acetonitrile) to a final concentration of $1 \mathrm{mM}$, which corresponded to the detection limit of product formation due to low activity. The reaction was followed for up to $200 \mathrm{~h}$ (measured every $24 \mathrm{~h}$ ). Cuvettes were stored at $37^{\circ} \mathrm{C}$ between measurements to allow for optimal activity. Control reactions of substrate $(10 \mu \mathrm{L})$ mixed with reaction buffer $(990 \mu \mathrm{L})$ were performed for both the amide and ester reactions, and the 
slopes of product formation versus time were subtracted from the corresponding reaction velocities of the enzyme catalyzed reaction.

\subsection{Molecular Dynamics Simulations}

Docking to identify an enzyme-assisted hydrogen bond acceptor to the reacting NH-group of amides was performed by capitalizing on a transition state structure for nitrogen inversion that we previously [29] obtained. Specifically, the TS geometry was obtained for the engineered I189A C. antarctica lipase B variant with $N$-ethyl butyramide as model substrate and using DFT at the B3LYP/6-31 $(\mathrm{d}, \mathrm{p})$ level of theory. The transition state structure was superposed on esterase scaffolds using the atoms of the catalytic serine and of the oxyanion hole as reference points in the quantum mechanical model and in the enzyme respectively. Molecular dynamics simulations on patatin from S. cardiophyllum (pat17) was based on the PDB file 1OXW [33] using YASARA [54] (Yet Another Scientific Artificial Reality Application) version 14.5.21 (YASARA biosciences, Vienna, Austria). Selenomethionines were replaced by methionines and all missing hydrogens were added to the starting enzyme structure, and the hydrogen network was optimized using the Amber03 force field. The structure was minimized through repeated steps of short molecular dynamics and energy minimizations, initially on all hydrogens, then by releasing fixed waters and finally on all atoms. The second tetrahedral intermediate during acylation was constructed by a covalent attachment of the amide substrate ( $p$-nitrobutyranilide) to the catalytic nucleophile (S77). The spatial placement of the substrate was guided by the location of a phosphonate inhibitor complexed to the enzyme [55]. The reacting NH-group was protonated to keep the negatively catalytic acid (D215) in a productive conformation during the MD simulations. A protonated second tetrahedral intermediate has been previously used as a model for the transition state of nitrogen inversion [35]. Force field parameterization for the substrate was obtained by the AUTOSMILES [56] methodology. All simulations were performed in a water box that contained approximately 8500 explicit water molecules. The $\mathrm{pH}$ was set to 7.5 with the adequate protonation states of enzyme side chains predicted by the built-in empirical method [57] in YASARA. The simulation cell was neutralized through the addition of $0.9 \% \mathrm{NaCl}$. The MD simulations were performed under the canonical ensemble at $298 \mathrm{~K}$ using a Berendsen thermostat (and the Amber03 force field as implemented in YASARA). PME accounted for long-range electrostatics [58] during the MD simulations that were performed for $90 \mathrm{~ns}$ in duplicate using different initial random seeds. A cut-off of $7.86 \AA$ for Van der Waals interactions was used.

Supplementary Materials: The following are available online at www.mdpi.com/2073-4344/6/6/90/s1. Figure S1: Modeling using a neutral reacting nitrogen atom leads to unproductive conformations; Figure S2: SDS-Page and Size Exclusion Chromatography of patatin; Figure S3: Experimental determination of enzyme kinetics; Figure S4: SDS-Page and ester activity measurement of the patatin knock-out mutant; Figure S5: Active site titration of patatin.

Acknowledgments: The Swedish Research Council (VR) is greatly acknowledged for financial support through a young investigator grant \#621-2013-5138 to P.-O. Syrén. The PDC Center for High Performance Computing at the KTH Royal Institute of Technology is acknowledged for providing computational support to P.-O. Syrén.

Author Contributions: C.K. performed active site titration, activity measurements, designed experiments, and helped in the writing of the manuscript. B.C. conceived protein expression, purification, and kinetics. P.O.S. performed MD simulations, designed experiments, and wrote the paper.

Conflicts of Interest: The authors declare no conflict of interest. The founding sponsors had no role in the design of the study; in the collection, analyses, or interpretation of data; in the writing of the manuscript; or in the decision to publish the results.

\section{Abbreviations}

The following abbreviations are used in this manuscript:

DFT density functional theory

SEC size exclusion chromatography

TS transition state

MD molecular dynamics 


\section{Appendix}

\section{A. Codon optimized sequence of patatin with an $\mathrm{N}$-terminal $\mathrm{His}_{6}$-tag}

ATGGGCCATCATCATCATCATCACGCGATGGCCCAACTGGGCGAAATGGTTACGGTCCTG TCGATTGACGGCGGCGGTATCCGTGGTATTATCCCGGCTACGATCCTGGAATTTCTGGAAGGC CAGCTGCAAGAAATGGATAACAATGCAGACGCTCGTCTGGCCGATTATTTTGACGTGATTGGC GGTACGTCAACCGGCGGTCTGCTGACGGCAATGATCTCGACCCCGAATGAAAACAATCGCCC GTTTGCGGCCGCAAAAGAAATTGTTCCGTTTTACTTCGAACATGGTCCGCAGATTTTCAACCC GAGCGGCCAAATCCTGGGTCCGAAATATGACGGCAAATACCTGATGCAGGTCCTGCAAGAA AAACTGGGTGAAACGCGTGTGCACCAGGCGCTGACCGAAGTGGTTATCAGCTCTTTCGATAT CAAAACGAACAAACCGGTGATTTTCACCAAATCAAACCTGGCGAATTCGCCGGAACTGGATG CCAAAATGTATGACATCTCATACTCGACCGCTGCCGCACCGACCTATTTTCCGCCGCATTACT TCGTTACGAACACCAGCAATGGCGATGAATATGAATTTAATCTGGTTGATGGTGCCGTTGCGA CCGTTGCCGATCCGGCACTGCTGAGCATTTCTGTTGCAACCCGTCTGGCTCAGAAAGACCCG GCATTTGCTAGTATCCGCTCCCTGAACTATAAGAAAATGCTGCTGCTGAGCCTGGGCACCGG TACCACGTCTGAATTCGATAAAACGTACACCGCAAAAGAAGCAGCTACGTGGACCGCTGTGC ACTGGATGCTGGTTATCCAAAAAATGACCGACGCGGCCAGTTCCTATATGACGGATTATTACC TGAGTACCGCATTCCAGGCTCTGGATTCCAAAAACAATTACCTGCGCGTCCAAGAAAACGCG CTGACCGGCACCACGACCGAAATGGATGACGCGAGCGAAGCCAACATGGAACTGCTGGTCC AAGTGGGTGAAAATCTGCTGAAAAAACCGGTTTCTGAAGATAACCCGGAAACCTATGAAGAA GCCCTGAAACGCTTCGCCAAACTGCTGTCAGACCGTAAAAAACTGCGTGCTAATAAAGCTTC ATACTAAGGATCC

\section{B. The patatin protein sequence used in the present work}

MGHHHHHHAMAQLGEMVTVLSIDGGGIRGIIPATILEFLEGQLQEMDNNADARLADYFDVIG GTSTGGLLTAMISTPNENNRPFAAAKEIVPFYFEHGPQIFNPSGQILGPKYDGKYLMQVLQEKLG ETRVHQALTEVVISSFDIKTNKPVIFTKSNLANSPELDAKMYDISYSTAAAPTYFPPHYFVTNTSNG DEYEFNLVDGAVATVADPALLSISVATRLAQKDPAFASIRSLNYKKMLLLSLGTGTTSEFDKTYTAKE AATWTAVHWMLVIQKMTDAASSYMTDYYLSTAFQALDSKNNYLRVQENALTGTTTEMDDASEAN MELLVQVGENLLKKPVSEDNPETYEEALKRFAKLLSDRKKLRANKASY*

\section{References}

1. Bornscheuer, U.T.; Huisman, G.W.; Kazlauskas, R.J.; Lutz, S.; Moore, J.C.; Robins, K. Engineering the third wave of biocatalysis. Nature 2012, 485, 185-194. [CrossRef] [PubMed]

2. Reetz, M.T. Biocatalysis in organic chemistry and biotechnology: Past, present, and future. J. Am. Chem. Soc. 2013, 135, 12480-12496. [CrossRef] [PubMed]

3. Both, P.; Busch, H.; Kelly, P.P.; Mutti, F.G.; Turner, N.J.; Flitsch, S.L. Whole-cell biocatalysts for stereoselective C-H amination reactions. Angew. Chem. Int. Ed. 2016, 55, 1511-1513. [CrossRef] [PubMed]

4. Siegel, J.B.; Smith, A.L.; Poust, S.; Wargacki, A.J.; Bar-Even, A.; Louw, C.; Shen, B.W.; Eiben, C.B.; Tran, H.M.; Noor, E.; et al. Computational protein design enables a novel one-carbon assimilation pathway. Proc. Natl. Acad. Sci. USA 2015, 112, 3704-3709. [CrossRef] [PubMed]

5. Edwards, D.R.; Lohman, D.C.; Wolfenden, R. Catalytic proficiency: The extreme case of S-O cleaving sulfatases. J. Am. Chem. Soc. 2012, 134, 525-531. [CrossRef] [PubMed]

6. Li, Q.; Qin, X.; Liu, J.; Gui, C.; Wang, B.; Li, J.; Ju, J. Deciphering the biosynthetic origin of L-allo-isoleucine. J. Am. Chem. Soc. 2016, 138, 408-415. [CrossRef] [PubMed]

7. Peter, D.M.; Schada von Borzyskowski, L.; Kiefer, P.; Christen, P.; Vorholt, J.A.; Erb, T.J. Screening and engineering the synthetic potential of carboxylating reductases from central metabolism and polyketide biosynthesis. Angew. Chem. Int. Ed. 2015, 54, 13457-13461. [CrossRef] [PubMed]

8. Nestl, B.M.; Hammer, S.C.; Nebel, B.A.; Hauer, B. New generation of biocatalysts for organic synthesis. Angew. Chem. Int. Ed. 2014, 53, 3070-3095. [CrossRef] [PubMed] 
9. Savile, C.K.; Janey, J.M.; Mundorff, E.C.; Moore, J.C.; Tam, S.; Jarvis, W.R.; Colbeck, J.C.; Krebber, A.; Fleitz, F.J.; Brands, J.; et al. Biocatalytic asymmetric synthesis of chiral amines from ketones applied to sitagliptin manufacture. Science 2010, 329, 305-309. [CrossRef] [PubMed]

10. Slaymaker, I.M.; Gao, L.; Zetsche, B.; Scott, D.A.; Yan, W.X.; Zhang, F. Rationally engineered Cas9 nucleases with improved specificity. Science 2016, 351, 84-88. [CrossRef] [PubMed]

11. Syren, P.-O.; Lindgren, E.; Hoeffken, H.W.; Branneby, C.; Maurer, S.; Hauer, B.; Hult, K. Increased activity of enzymatic transacylation of acrylates through rational design of lipases. J. Mol. Catal. B Enzym. 2010, 65, 3-10. [CrossRef]

12. Schmidt, S.; Scherkus, C.; Muschiol, J.; Menyes, U.; Winkler, T.; Hummel, W.; Groeger, H.; Liese, A.; Herz, H.-G.; Bornscheuer, U.T. An enzyme cascade synthesis of $\varepsilon$-caprolactone and its oligomers. Angew. Chem. Int. Ed. 2015, 54, 2784-2787. [CrossRef] [PubMed]

13. Chang, M.C.Y.; Keasling, J.D. Production of isoprenoid pharmaceuticals by engineered microbes. Nat. Chem. Biol. 2006, 2, 674-681. [CrossRef] [PubMed]

14. Coelho, P.S.; Wang, Z.J.; Ener, M.E.; Baril, S.A.; Kannan, A.; Arnold, F.H.; Brustad, E.M. A serine-substituted P450 catalyzes highly efficient carbene transfer to olefins in vivo. Nat. Chem. Biol. 2013, 9, 485-487. [CrossRef] [PubMed]

15. Renata, H.; Wang, Z.J.; Arnold, F.H. Expanding the enzyme universe: Accessing non-natural reactions by mechanism-guided directed evolution. Angew. Chem. Int. Ed. 2015, 54, 3351-3367. [CrossRef] [PubMed]

16. Seitz, M.; Syren, P.-O.; Steiner, L.; Klebensberger, J.; Nestl, B.M.; Hauer, B. Synthesis of heterocyclic terpenoids by promiscuous squalene-hopene cyclases. ChemBioChem 2013, 14, 436-439. [CrossRef] [PubMed]

17. Khersonsky, O.; Tawfik, D.S. Enzyme promiscuity: A mechanistic and evolutionary perspective. Annu. Rev. Biochem. 2010, 79, 471-505. [PubMed]

18. Hult, K.; Berglund, P. Enzyme promiscuity: Mechanism and applications. Trends Biotechnol. 2007, 25, $231-238$. [CrossRef] [PubMed]

19. Ollis, D.L.; Cheah, E.; Cygler, M.; Dijkstra, B.; Frolow, F.; Franken, S.M.; Harel, M.; Remington, S.J.; Silman, I.; Schrag, J.; et al. The alpha/beta hydrolase fold. Protein Eng. 1992, 5, 197-211. [CrossRef] [PubMed]

20. Rauwerdink, A.; Kazlauskas, R.J. How the same core catalytic machinery catalyzes 17 different reactions: The serine-histidine-aspartate catalytic triad of $\alpha / \beta$-hydrolase fold enzymes. ACS Catal. 2015, 5, 6153-6176. [CrossRef]

21. Brieke, C.; Peschke, M.; Haslinger, K.; Cryle, M.J. Sequential in vitro cyclization by cytochrome P450 enzymes of glycopeptide antibiotic precursors bearing the $x$-domain from nonribosomal peptide biosynthesis. Angew. Chem. Int. Ed. 2015, 54, 15715-15719. [CrossRef] [PubMed]

22. Steele, C.L.; Crock, J.; Bohlmann, J.; Croteau, R. Sesquiterpene synthases from grand fir (Abies grandis). Comparison of constitutive and wound-induced activities, and cdna isolation, characterization, and bacterial expression of $\delta$-selinene synthase and $\gamma$-humulene synthase. J. Biol. Chem. 1998, 273, 2078-2089. [CrossRef] [PubMed]

23. Steinkeller, G.; Gruber, C.C.; Pavkov-Keller, T.; Binter, A.; Steiner, K.; Winkler, C.; Łyskowski, A.; Schwamberger, O.; Oberer, M.; Schwab, H.; et al. Identification of promiscuous ene-reductase activity by mining structural databases using active site constellations. Nat. Commun. 2014, 5, 4150. [CrossRef]

24. Höhne, M.; Schätzle, S.; Jochens, H.; Robins, K.; Bornscheuer, U.T. Rational assignment of key motifs for function guides in silico enzyme identification. Nat. Chem. Biol. 2010, 6, 807-813. [CrossRef] [PubMed]

25. Schellenberger, V.; Braune, K.; Hofmann, H.-J.; Jakubke, H.-D. The specificity of chymotrypsin. Eur. J. Biochem. 1991, 199, 623-636. [CrossRef] [PubMed]

26. Syren, P.-O.; Hult, K. Amidases have a hydrogen bond that facilitates nitrogen inversion, but esterases have not. ChemCatChem 2011, 3, 853-860. [CrossRef]

27. Syren, P.-O. The solution of nitrogen inversion in amidases. FEBS J. 2013, 280, 3069-3083. [CrossRef] [PubMed]

28. Ekici, O.D.; Paetzel, M.; Dalbey, R.E. Unconventional serine proteases: Variations on the catalytic Ser/His/Asp triad configuration. Protein Sci. 2008, 17, 2023-2037. [CrossRef] [PubMed]

29. Hendil-Forssell, P.; Martinelle, M.; Syren, P.-O. Exploring water as building bricks in enzyme engineering. Chem. Commun. 2015, 51, 17221-17224. [CrossRef] [PubMed] 
30. Devamani, T.; Rauwerdink, A.M.; Lunzer, M.; Jones, B.J.; Mooney, J.L.; Tan, M.A.O.; Zhang, Z.-J.; Xu, J.-H.; Dean, A.M.; Kazlauskas, R.J. Catalytic promiscuity of ancestral esterases and hydroxynitrile lyases. J. Am. Chem. Soc. 2016, 138, 1046-1056. [CrossRef] [PubMed]

31. Harms, M.J.; Thornton, J.W. Analyzing protein structure and function using ancestral gene reconstruction. Curr. Opin. Struct. Biol. 2010, 20, 360-366. [CrossRef] [PubMed]

32. Risso, V.A.; Gavira, J.A.; Mejia-Carmona, D.F.; Gaucher, E.A.; Sanchez-Ruiz, J.M. Hyperstability and substrate promiscuity in laboratory resurrections of precambrian $\beta$-lactamases. J. Am. Chem. Soc. 2013, 135, 2899-2902. [CrossRef] [PubMed]

33. Rydel, T.J.; Williams, J.M.; Krieger, E.; Moshiri, F.; Stallings, W.C.; Brown, S.M.; Pershing, J.C.; Purcell, J.P.; Alibhai, M.F. The crystal structure, mutagenesis, and activity studies reveal that patan is a lipid acyl hydrolase with a Ser-Asp catalytic dyad. Biochemistry 2003, 42, 6696-6708. [CrossRef] [PubMed]

34. Syren, P.-O.; Hendil-Forssell, P.; Aumailley, L.; Besenmatter, W.; Gounine, F.; Svendsen, A.; Martinelle, M.; Hult, K. Esterases with an introduced amidase-like hydrogen bond in the transition state have increased amidase specificity. ChemBioChem 2012, 13, 645-648. [CrossRef] [PubMed]

35. Syren, P.-O.; Le Joubioux, F.; Ben Henda, Y.; Maugard, T.; Hult, K.; Graber, M. Proton shuttle mechanism in the transition state of lipase-catalyzed n-acylation of amino alcohols. ChemCatChem 2013, 5, 1842-1853. [CrossRef]

36. Deslongchamps, P. Stereoelectronic control in the cleavage of tetrahedral intermediates in the hydrolysis of esters and amides. Tetrahedron 1975, 31, 2463-2490. [CrossRef]

37. Bachovchin, D.A.; Cravatt, B.F. The pharmacological landscape and therapeutic potential of serine hydrolases. Nat. Rev. Drug Discov. 2012, 11, 52-68. [CrossRef] [PubMed]

38. Dessen, A.; Tang, J.; Schmidt, H.; Stahl, M.; Clark, J.D.; Seehra, J.; Somers, W.S. Crystal structure of human cytosolic phospholipase A2 reveals a novel topology and catalytic mechanism. Cell 1999, 97, 349-360. [CrossRef]

39. Hackenschmidt, S.; Moldenhauer, E.J.; Behrens, G.A.; Gand, M.; Pavlidis, I.V.; Bornscheuer, U.T. Enhancement of promiscuous amidase activity of a bacillus subtilis esterase by formation of a $\pi-\pi$ network. ChemCatChem 2014, 6, 1015-1020. [CrossRef]

40. Lenski, R.E.; Wiser, M.J.; Ribeck, N.; Blount, Z.D.; Nahum, J.R.; Morris, J.J.; Zaman, L.; Turner, C.B.; Wade, B.D.; Maddamsetti, R.; et al. Sustained fitness gains and variability in fitness trajectories in the long-term evolution experiment with escherichia coli. Proc. R. Soc. B 2015, 282, 20152292. [CrossRef] [PubMed]

41. Keeling, C.I.; Weisshaar, S.; Ralph, S.G.; Jancsik, S.; Hamberger, B.; Dullat, H.K.; Bohlmann, J. Transcriptome mining, functional characterization, and phylogeny of a large terpene synthase gene family in spruce (Picea spp.). BMC Plant Biol. 2011, 11, 43. [CrossRef] [PubMed]

42. Powles, S.B.; Yu, Q. Evolution in action: Plants resistant to herbicides. Annu. Rev. Plant Biol. 2010, 61, 317-347. [CrossRef] [PubMed]

43. Martin, R.E.; Marchetti, R.V.; Cowan, A.I.; Howitt, S.M.; Broeer, S.; Kirk, K. Chloroquine transport via the malaria parasite's chloroquine resistance transporter. Science 2009, 325, 1680-1682. [CrossRef] [PubMed]

44. Hammer, S.C.; Marjanovic, A.; Dominicus, J.M.; Nestl, B.M.; Hauer, B. Squalene hopene cyclases are protonases for stereoselective bronsted acid catalysis. Nat. Chem. Biol. 2015, 11, 121-126. [CrossRef] [PubMed]

45. Constable, D.J.C.; Dunn, P.J.; Hayler, J.D.; Humphrey, G.R.; Leazer, J.L., Jr.; Linderman, R.J.; Lorenz, K.; Manley, J.; Pearlman, B.A.; Wells, A.; et al. Key green chemistry research Areas-A perspective from pharmaceutical manufacturers. Green Chem. 2007, 9, 411-420. [CrossRef]

46. Thayer, A.M. Making peptides at large scale. Chem. Eng. News 2011, 89, 21-25.

47. Ku, B.; Lee, K.-H.; Park, W.S.; Yang, C.-S.; Ge, J.; Lee, S.-G.; Cha, S.-S.; Shao, F.; Heo, W.D.; Jung, J.U.; et al. Vipd of legionella pneumophila targets activated Rab5 and Rab22 to interfere with endosomal trafficking in macrophages. PLoS Pathog. 2012, 8, e1003082. [CrossRef] [PubMed]

48. Bergeret, F.; Gavalda, S.; Chalut, C.; Malaga, W.; Quemard, A.; Pedelacq, J.-D.; Daffe, M.; Guilhot, C.; Mourey, L.; Bon, C. Biochemical and structural study of the atypical acyltransferase domain from the mycobacterial polyketide synthase Pks13. J. Biol. Chem. 2012, 287, 33675-33690. [CrossRef] [PubMed]

49. Kourist, R.; Bartsch, S.; Fransson, L.; Hult, K.; Bornscheuer, U.T. Understanding promiscuous amidase activity of an esterase from bacillus subtilis. ChemBioChem 2008, 9, 67-69. [CrossRef] [PubMed] 
50. Hedstrom, L. Serine protease mechanism and specificity. Chem. Rev. 2002, 102, 4501-4524. [CrossRef] [PubMed]

51. Bradford, M.M. A rapid and sensitive method for the quantitation of microgram quantities of protein utilizing the principle of protein-dye binding. Anal. Biochem. 1976, 72, 248-254. [CrossRef]

52. Magnusson, A.O.; Rotticci-Mulder, J.C.; Santagostino, A.; Hult, K. Creating space for large secondary alcohols by rational redesign of candida antarctica lipase B. ChemBioChem 2005, 6, 1051-1056. [CrossRef] [PubMed]

53. Janes, L.E. Screening Methods to Identify Stereoselective Hydrolases for Synthetic Applications. Ph.D. Thesis, Department of Chemistry, McGill University, Montreal, QC, Canada, 1998.

54. Krieger, E.; Darden, T.; Nabuurs, S.B.; Finkelstein, A.; Vriend, G. Making optimal use of empirical energy functions: Force-field parameterization in crystal space. Proteins Struct. Funct. Bioinform. 2004, 57, 678-683. [CrossRef] [PubMed]

55. Wijeyesakere, S.J.; Richardson, R.J.; Stuckey, J.A. Crystal Structure of Patatin-17 in Complex with Aged and Non-Aged Organophosphorus Compounds. PLoS ONE 2014, 9, e108245. [CrossRef] [PubMed]

56. Jakalian, A.; Jack, D.B.; Bayly, C.I. Fast, efficient generation of high-quality atomic charges. AM1-BCC model: II. Parameterization and validation. J. Comput. Chem. 2002, 23, 1623-1641. [CrossRef] [PubMed]

57. Krieger, E.; Nielsen, J.E.; Spronk, C.A.E.M.; Vriend, G. Fast empirical Pka prediction by ewald summation. J. Mol. Graph. Model. 2006, 25, 481-486. [CrossRef] [PubMed]

58. Essmann, U.; Perera, L.; Berkowitz, M.L.; Darden, T.; Lee, H.; Pedersen, L.G. A smooth particle mesh ewald method. J. Chem. Phys. 1995, 103, 8577-8593. [CrossRef]

(C) 2016 by the authors; licensee MDPI, Basel, Switzerland. This article is an open access article distributed under the terms and conditions of the Creative Commons Attribution (CC-BY) license (http:/ / creativecommons.org/licenses/by/4.0/). 